\title{
Taxonomy of Manufacturing Flexibility at Manufacturing Companies Using Imperialist Competitive Algorithms, Support Vector Machines and Hierarchical Cluster Analysis
}

\author{
Mehdi Khoobiyan \\ Department of \\ Management, Ferdowsi \\ University of Mashhad, \\ Mashhad, Iran \\ khoobiyanm@yahoo.com
}

\author{
Alireza Pooya \\ Department of \\ Management, Ferdowsi \\ University of Mashhad, \\ Mashhad, Iran \\ Alirezapooya@um.ac.ir
}

\author{
Ahmad Tavakkoli \\ Department of \\ Management, Ferdowsi \\ University of Mashhad, \\ Mashhad, Iran \\ tavakoli-a@um.ac.ir
}

\author{
Fariborz Rahimnia \\ Department of \\ Management, Ferdowsi \\ University of Mashhad, \\ Mashhad, Iran \\ r-nia@um.ac.ir
}

\begin{abstract}
Manufacturing flexibility is a multidimensional concept and manufacturing companies act differently in using these dimensions. The purpose of this study is to investigate taxonomy and identify dominant groups of manufacturing flexibility. Dimensions of manufacturing flexibility are extracted by content analysis of literature and expert judgements. Manufacturing flexibility was measured by using a questionnaire developed to survey managers of manufacturing companies. The sample size was set at 379 . To identify dominant groups of flexibility based on dimensions of flexibility determined, Hierarchical Cluster Analysis (HCA), Imperialist Competitive Algorithms (ICAs) and Support Vector Machines (SVMs) were used by cluster validity indices. The best algorithm for clustering was SVMs with three clusters, designated as leading deliverybased flexibility, frugal flexibility and sufficient plan-based flexibility.
\end{abstract}

Keywords-manufacturing flexibility; taxonomy; dominant groups; hierarchical cluster analysis; support vector machines; imperialist competitive algorithm.

\section{INTRODUCTION}

In a stable environment, the concept of traditional management helps organizations achieve success. However, this management approach is restricted in preparing organizations to deal with environmental uncertainty. For this reason, new management theories have focused on the development of flexibility as an alternative approach for traditional management [1]. Adaptability of a company with environmental uncertainty is heavily influenced by manufacturing flexibility [2]. In [3], authors stated that customer satisfaction and supplier trust is a key success in turbulent environments in which frequent changes are made in product features and volume of demand; to achieve these goals, the company needs flexibility. Meanwhile, it seems reasonable to employ a manufacturing strategy which is the effective utilization of manufacturing capabilities as a competitive tool in order to achieve organizational goals and improve performance. One of the most important manufacturing capabilities is manufacturing flexibility; according to [4], manufacturing flexibility refers to the ability to change or to meet or achieve minimum loss in time, cost and performance. Recent economic developments indicate that manufacturing flexibility is more important than ever; flexibility is considered as the main goal of many manufacturing systems [5]. During the recent decade, manufacturing flexibility has been addressed by academy and industry; moreover, research has been done on definitions, classification and identification of different dimensions of flexible manufacturing [6-9]. Investment in manufacturing flexibility enables organizations to reconfigure or reduce uncertainty and create competitive position, or hold their capabilities to understand future uncertainty in order to adapt to uncertainty better [10]. Manufacturing flexibility can be a vital and definitive source of competitive advantage, although it is the most difficult goal to achieve [4, 11].

In [12], author distinguished the difficulty in achieving manufacturing flexibility; as he suggested, this should not be considered as a commodity which can be bought from shops and used directly, but rather, it should be carefully planned and managed [13-16]. It is assumed that the organization can be flexible in some ways and less flexible in some others. Managers should focus on proper dimensions of adaptation to their company and develop a particular set of manufacturing flexibility [17]. Manufacturing flexibility has diverse dimensions and nature. Its dimensions were first introduced in [18] as flexibility of machine, process, product, production line, production volumes, development, operation and production. Interestingly, two studies conducted to determine types of manufacturing flexibility in organizations provided similar results; however, they addressed the same industry and there are similar competitive features in a specific industry [6]. In [5], authors stated that a certain degree of manufacturing flexibility is a future priority. Dimensions of flexibility applied 
to any organization do not necessarily improve performance and may even reduce it; therefore, additional time and expense spent to implement dimensions which do not fit manufacturing organizations should be avoided [19, 20]. As noted earlier, works such as [17-18, 21] presented different dimensions for manufacturing flexibility of industrial organizations and showed that organizations use different dimensions of manufacturing flexibility based on their conditions and characteristics. In $[6,17]$ it was proposed that different organizations need to focus on different dimensions of manufacturing flexibility.

However, none of these works have determined a harmonious and congruent combination of dimensions which can be planned and implemented in a company. In other words, they have not determined the dominant groups of manufacturing flexibility and their dimensions which are more efficient and effective for a company. In addition to the identification of these dimensions, manufacturing companies with different characteristics need to know the above factors, an issue that is addressed in this study. Moreover, this study compares different algorithms for taxonomy and selection of dominant groups of manufacturing flexibility to select the best clusters by choosing the most efficient algorithm by cluster validity indices. For this purpose, this study reviews the literature and determines dimensions of manufacturing flexibility to identify the dominant groups of manufacturing flexibility; finally, different dominant strategic groups of flexibility are designated and conclusions and suggestions are made for future studies.

\section{LITERATURE REVIEW}

Management literature shows that flexibility is considered a positive asset [22]. Organizations require flexible manufacturing to manage uncertainties in their environment [23]. However, since term flexibility is used excessively, its detailed concept is not clear [24]. In general, flexibility can be considered as an indicator linking the system and its external environment to absorb uncertainty, dynamics of the system as well as the ability to change and adapt [25]. Scholars have used different types of flexibility for manufacturing flexibility. For example, in [9] authors divided flexibility in three groups: flexibility in decision making theory, flexibility in economy theory and flexibility in manufacturing systems. In the past few decades, the concept of manufacturing flexibility has been a key competitive criterion for many manufacturing organizations. A series of studies has been performed by different scholars on different aspects of flexibility [26]. In [27], authors stated that the above concept refers to the ability of the manufacturing system to adapt to changing and dynamic environment; another appropriate definition can be the ability of the system to cope with changes related to devices, processes and products [28]. However, in [2] authors stated that flexible manufacturing is the ability to produce a great variety of key features of the product; in overall, manufacturing flexibility can only be seen in output. The most inclusive definition which has been raised so far is the ability to change or react with the least possible loss in time, cost and performance [24]. All definitions specify three points: first, they all determine the extent and diversity of the subject; second, they agree that flexibility is the ability to respond to change; third, that flexibility has been proposed against uncertainty.

According to [29], evidence shows discrepancies in existing definitions of flexibility; it is thus proposed that the concept is not well understood yet. To understand flexibility, it is essential to consider various aspects such as definition of flexibility, types of flexibility, criteria of flexibility and its effect on investment decisions [30]. Manufacturing flexibility is a multidimensional phenomenon. In [18], authors presented eight dimensions of flexibility including machine, process, product, production line, production volume, extension, operation and production; then, other dimensions such as handling, labor, plan, market, delivery, moderation and services were added to the above dimensions [31]. A number of scholars have addressed manufacturing flexibility with a special glance at several dimensions. For example, in [32] eight dimensions were identified and in [33] eleven dimensions were identified. There are different classification logics including horizontal classification, vertical classification, time-based classification, target-based classification and combined classification for interpretation of various aspects of manufacturing flexibility [25]. In [6], authors presented a new classification for types of manufacturing flexibility. In [26], it was showed that manufacturing flexibility and labor flexibility has a positive effect on product innovation. In [34], it was concluded that formal organizational structures along with manufacturing flexibility improve performance. In [29], authors presented a new classification of previously known flexibilities. Essential flexibility includes machine, product, labor, transportation, track and volume; components of sufficient flexibility include processes, operations, plans and materials; components of competitive flexibility include production, development and market. In [2], authors developed a model which considered manufacturing flexibility as a dynamic capability. In [3], authors presented a new business model for flexible organizations. In [35] 6 widely used dimensions of flexibility were measured. In [36] drivers and factors of flexibility in an unpredictable, unstable and operational environment of manufacturers were discussed. In [37], a conceptual model by using only two dimensions, production volume and process, was developed to show the effect of manufacturing flexibility on performance.

According to $[18,31-33]$ that identified dimensions of manufacturing flexibility, the present study comprehensively addresses these dimensions, taxonomy of manufacturing companies based on these dimensions by comparing different grouping techniques and determines dominant groups of flexibility.

\section{MATERIALS AND METHODS}

\section{A. Population and Sample}

This study addressed manufacturing flexibility in 379 manufacturing companies from seven industries as listed in Table I. The distributed questionnaires were filled by top managers. 
TABLE I. THE STUDIED COMPANIES

\begin{tabular}{|c|c|c|c|c|c|c|c|c|c|}
\hline \multicolumn{2}{|l|}{ Industry } & $\begin{array}{c}\text { Food \& } \\
\text { Beverage }\end{array}$ & Metal & $\begin{array}{l}\text { Electrical \& } \\
\text { Electronics }\end{array}$ & Chemical & Textile & Cellulose & Non-metallic mineral & Total \\
\hline \multirow{2}{*}{ Studied company } & $\mathrm{N}$ & 135 & 144 & 35 & 26 & 19 & 11 & 9 & 379 \\
\hline & $\%$ & 36 & 38 & 9 & 7 & 5 & 3 & 2 & 100 \\
\hline
\end{tabular}

\section{B. Data Collection and Validation}

Content analysis was used to identify the dimensions of manufacturing flexibility. Based on this analysis, 18 dimensions of manufacturing flexibility were identified and are listed in Table II. To enrich the analysis, ten academic and industrial experts were asked to review the dimensions and provide their feedbacks about their relationship with flexibility and their differentiation from other dimensions. Then, three dimensions including quality of input materials, quality and automation were discarded because their score was less than mean. New design was also considered as a part of new product; thus, this dimension was also discarded.

TABLE II. DIMENSIONS OF MANUFACTURING FLEXIBILITY

\begin{tabular}{|c|c|c|c|}
\hline & Dimensions & Definition & Literature \\
\hline 1 & New product & Ability to change current product or produce new product quickly at minimal cost & {$[6,11,17,21,23,25,28-29,31-36]$} \\
\hline 2 & Production volume & Ability to take orders and produce at different volumes ranging from low to high profitably & {$[6,11,21,23,25,28-29,31-36]$} \\
\hline 3 & $\begin{array}{l}\text { Machine } \\
\text { (machines) }\end{array}$ & $\begin{array}{l}\text { Ability to perform various operations by machine without the need for spending too much } \\
\text { time and cost to shift from one operation to another }\end{array}$ & {$[6,11,21,23,25,28-29,31-35]$} \\
\hline 4 & Material handling & $\begin{array}{c}\text { Ability of material handling system to transfer materials effectively to different parts in } \\
\text { proper situations and process them for the required production unit }\end{array}$ & {$[6,11,21,23,25,28-29,31-35]$} \\
\hline 5 & $\begin{array}{l}\text { Product mix } \\
\text { (process) }\end{array}$ & $\begin{array}{c}\text { Ability to produce a large variety of products without inclusion of fines or large changes in } \\
\text { performance of the final product }\end{array}$ & {$[21,23,26,29,32-37]$} \\
\hline 6 & Extension & Ease of development of system capacity at the right time & {$[6,11,21,25,28-29,31-33]$} \\
\hline 7 & Labor & Ability of personnel to perform various tasks and their multidisciplinary nature & {$[21,23,26,29,32-36]$} \\
\hline 8 & Routing & Ability to produce alternative routes (by different machines and operations) & {$[6,11,21,23,25,28-29,31,33]$} \\
\hline 9 & Plan & $\begin{array}{l}\text { Ability of the system to work continuously without supervision and inspection (as long as } \\
\text { the system can work without supervision, inspection, repair and maintenance) }\end{array}$ & {$[6,11,23,25,28-29,31]$} \\
\hline 10 & Market & Ability to adapt the production system easily to changing market conditions & {$[6,11,25,28-29,31-32]$} \\
\hline 11 & Production & Ability to produce diverse parts / products without adding capital equipment & {$[6,11,25,28-29,31]$} \\
\hline 12 & Operations & $\begin{array}{l}\text { Ability to produce by different methods with alternative processing schemes or through } \\
\text { interaction with or replacement of some operations by other types of operations }\end{array}$ & {$[6,21,25,28-29,31]$} \\
\hline 13 & Delivery & $\begin{array}{c}\text { Ability to shorten and extend delivery time and ability to prepare changing demands in a } \\
\text { short time }\end{array}$ & {$[6,23,33,36]$} \\
\hline 14 & Modification & $\begin{array}{l}\text { Ability to correct products without inclusion of fines or large changes in performance of } \\
\text { final product }\end{array}$ & {$[21,35]$} \\
\hline 15 & $\begin{array}{l}\text { Quality of input } \\
\text { materials }\end{array}$ & Ability to use different quality inputs & {$[29,33]$} \\
\hline 16 & Quality & Ability of the system to change quality of product or products to fit the market demand & {$[36]$} \\
\hline 17 & Automation & Level of automation and computerization of manufacturing technologies & [6] \\
\hline 18 & New design & Ability to design and introduce the product rapidly to the manufacturing system & [6] \\
\hline
\end{tabular}

Then, the manufacturing flexibility questionnaire was developed based on 14 dimensions remaining. This questionnaire was composed of two parts; the first part involved demographic variables and the second part consisted of 14 dimensions and 45 scales. The questions were scored on a 5-point scale from very low to very high. The questionnaires were distributed among top managers of manufacturing companies. To avoid ambiguity, problems of managers with the questionnaire were resolved in person. Content validity was used to validate the questionnaire. First, dimensions were extracted and listed in tables with their definitions in Farsi and English and references; the listed dimensions were modified and approved by academic experts. Second, the scales related to each dimension were listed in tables with their definitions in Farsi and English and references and presented to experts; the listed scales were modified and approved by academic experts. Third, dimensions and scales were presented to industrial experts; once they approved the dimensions and scales, the questionnaire was designed and used. Convergent validity was used to determine construct validity by using confirmatory factor analysis (CFA). Varimax rotation was used to validate the manufacturing flexibility questionnaire. KMO of a construct represents sampling adequacy for factor analysis. Significance level of Bartlett's test also shows that factor analysis can be used to identify constructs. There are different methods which can be used to determine reliability of the questionnaire. One of these methods is internal consistency.

\section{Data Analysis}

Hierarchical Cluster Analysis (HCA), Imperialist Competitive Algorithms (ICAs) and Support Vector Machines (SVMs) were used to cluster and identify dominant groups of manufacturing flexibility. MATLAB and R were the software used. Six cluster validity indices were used to compare results of three algorithms and select the best results. Clustering refers to splitting a heterogeneous group into several homogeneous 
subgroups to maximize between-group difference and minimize within-group difference [38]. There are two types of cluster analysis, hierarchical and non-hierarchical; hierarchical clustering is known as the most widely used cluster analysis. Since the number of flexible clusters was not clear initially, HCA was used in this study. SVMs can be considered as one of the most effective statistical training methods for classifying data. SVMs acts by findings support vectors and finding linear machines at high-dimensional feature space but non-linearly associated with input data space. SVMs are widely used as a fast method for classifying data [39].

ICAs are one of the new meta-heuristic methods [40]. Although ICAs has been invented for few years, they been used in many problems such as skeletal structure design [41], data clustering [42], linear induction motor [43]. In addition to their efficiency, rapid convergence and high ability to optimize compared to existing algorithms [44], ICAs are highly preferred for their innovation and attractiveness. There are different methods and indices used to validate the results of clustering by different algorithms. This study used six cluster validity indices noted by different works such as [45-47]. The most efficient algorithm was the one in which all six indices were in better position. These indices included Davies and Bouldin index, Dunn index, GDI11 index, WemmertGancarski index, Ratkowsky-Lance index, and CalinskiHarabasz index. Note that the best value is characterized by the least value for Davies and Bouldin index and the highest value for other indices.

\section{RESULtS}

\section{A. Validity and Reliability}

As shown in Table III, KMO $>0.5$, p-value $<0.05$ and $\alpha>0.6$ indicate good validity and reliability of the questionnaire.

\section{B. Taxonomic Results}

Since the number of clusters was not clear initially in HCA, dendrograms of 379 observations were plotted. Figure 1 shows the dendrogram of 379 companies. According to the dendrogram and placement of observations in clusters, judgements can be made about the number of clusters. As shown in the figure, there are at least 5 clusters in the dendrogram.

To evaluate minimum and maximum clusters possible, the number of clusters was set at 3 to 8 and observations were examined by six indices. The results are presented in Table IV. The best number of clusters for HCA was six. To cluster by SVMs, it is required to use a primary clustering. For this purpose, a part of data (data related to 100 companies) was used as training data based on which the model was trained. Then, all data was used for clustering. Primary clustering was done initially; training data was clustered by using k-means in 100 iterations assuming five clusters. The result was used to train the SVMs. The second row of Table IV shows the results of 3 to 8 clusters examined by six different indices in SVMs.
As the results show, the best number of clusters was three. Three to eight clusters were created and the output was used for examining the indices. The third row of Table IV shows the results of ICAs for different indices. As the results show, the best number of clusters was three.

\section{Comparison of Different Clustering Algorithms to Select the Most Efficient Algorithm}

Table $\mathrm{V}$ was developed by considering the best number of clusters identified in Table IV. This table lists the value of evaluation criteria for the selected number of clusters. For example, 0.1771 is the value of Wemmert-Gancarski for six clusters, and so on. As noted earlier, the best value is the least for Davies-Bouldin and the highest for other indices. Therefore, the best values of indices in different algorithms and consequently the best algorithm are listed in the fifth and sixth row of Table V. The sixth row shows the selected number of clusters for the selected algorithm. As shown in the table, three clusters have the highest selection in different indices.

\section{Cluster Designation}

Considering three clusters for SVMs, Table VI lists the results of cluster analysis for mean of different dimensions, rank of each dimension in each cluster and among other clusters.

\section{1) Cluster 1: delivery-based leading flexibility cluster}

Cluster 1 was the first between three clusters in terms of production volume, new product, process, extension, labor, market, production, delivery and modification; moreover, delivery was the first dimension within the cluster 1 . Thus, cluster 1 was designated as delivery-based leading flexibility cluster. Therefore, it can be claimed that the companies located in this cluster are leading in a large number of dimensions of flexibility and particularly consider delivery. They are able to deliver goods at different times to meet customer demand.

\section{2) Cluster 2: frugal flexibility}

Cluster 2 was designated as frugal flexibility cluster. Similar to the essential flexibility cluster of [29] which was the top priority in terms of machinery and routing, machinery and routing were the first in the cluster 2 between clusters and other dimensions were the third. Within the cluster 2 , machinery was the first. This indicates flexibility of machinery and the ability to perform different operations by machinery in this group.

\section{3) Cluster 3: plan-based sufficient flexibility}

The third cluster was designated as plan-based sufficient flexibility. The cluster 3 was the first between other clusters in terms of material handling, operation and plan. Sufficient flexibility cluster of [29] also involved operation and plan. The plan-based sufficient flexibility cluster was the second between clusters in terms of other dimensions. Plan was the first within the cluster 3; this indicates particular attention to system planning in this cluster. The companies located in this cluster can operate without monitoring and inspection for a longer time. 
TABLE III. VALIDITY AND RELIABILITY OF MANUFACTURING FLEXIBILITY QUESTIONNAIRE

\begin{tabular}{|c|c|c|c|c|c|c|c|}
\hline Construct & Scale & Factor loading & KMO & Bartlett & Iteration & Adjusted variance & $\alpha$ \\
\hline \multirow{7}{*}{$\begin{array}{l}\text { Product mix } \\
\text { MI }\end{array}$} & MI1 & 0.76 & \multirow{7}{*}{0.79} & 0 & 1 & \multirow{7}{*}{0.68} & \multirow{7}{*}{0.78} \\
\hline & MI2 & 0.65 & & 0 & 1 & & \\
\hline & MI3 & 0.5 & & 0 & 1 & & \\
\hline & MI4 & 0.75 & & 0 & 1 & & \\
\hline & MI5 & 0.5 & & 0 & 1 & & \\
\hline & MI6 & 0.59 & & 0 & 1 & & \\
\hline & MI7 & 0.51 & & 0 & 1 & & \\
\hline \multirow{2}{*}{$\begin{array}{c}\text { Production volume } \\
\text { V } \\
\end{array}$} & V1 & 0.73 & \multirow{2}{*}{0.58} & 0 & 1 & \multirow{2}{*}{0.63} & \multirow{2}{*}{0.6} \\
\hline & V2 & 0.73 & & 0 & 1 & & \\
\hline \multirow{3}{*}{$\begin{array}{c}\text { New product } \\
\text { NP }\end{array}$} & NP1 & 0.76 & \multirow{3}{*}{0.63} & 0 & 1 & \multirow{3}{*}{0.64} & \multirow{3}{*}{0.67} \\
\hline & NP2 & 0.81 & & 0 & 1 & & \\
\hline & NP3 & 0.65 & & 0 & 1 & & \\
\hline \multirow{3}{*}{$\begin{array}{l}\text { Machine } \\
\text { MA }\end{array}$} & MA1 & 0.68 & \multirow{3}{*}{0.61} & 0 & 1 & \multirow{3}{*}{0.66} & \multirow{3}{*}{0.69} \\
\hline & MA2 & 0.77 & & 0 & 1 & & \\
\hline & MA3 & 0.64 & & 0 & 1 & & \\
\hline \multirow{6}{*}{$\begin{array}{c}\text { Material handling } \\
\text { MH }\end{array}$} & MH1 & 0.56 & \multirow{6}{*}{0.72} & 0 & 1 & \multirow{6}{*}{0.69} & \multirow{6}{*}{0.71} \\
\hline & MH2 & 0.53 & & 0 & 1 & & \\
\hline & MH3 & 0.5 & & 0 & 1 & & \\
\hline & MH4 & 0.72 & & 0 & 1 & & \\
\hline & MH5 & 0.51 & & 0 & 1 & & \\
\hline & MH6 & 0.49 & & 0 & 1 & & \\
\hline \multirow{3}{*}{$\begin{array}{c}\text { Extension } \\
\text { E }\end{array}$} & E1 & 0.76 & \multirow{3}{*}{0.64} & 0 & 1 & & \\
\hline & E2 & 0.73 & & 0 & 1 & 0.65 & 0.68 \\
\hline & E3 & 0.73 & & 0 & 1 & & \\
\hline & L1 & 0.48 & & 0 & 1 & & \\
\hline Labor & L2 & 0.78 & 0.66 & 0 & 1 & 0.63 & 0.67 \\
\hline & L3 & 0.78 & & 0 & 1 & & \\
\hline Routing & RO1 & 0.68 & & 0 & 1 & & \\
\hline RO & RO2 & 0.68 & 0.59 & 0 & 1 & 0.62 & 0.65 \\
\hline Plan & P1 & 0.5 & & 0 & 1 & & \\
\hline $\mathrm{P}$ & $\mathrm{P} 2$ & 0.5 & 0.61 & 0 & 1 & 0.62 & 0.69 \\
\hline Market & MAR1 & 0.67 & & 0 & 1 & & \\
\hline MAR & MAR2 & 0.67 & 0.54 & 0 & 1 & 0.57 & 0.6 \\
\hline Production & PR1 & 0.62 & & 0 & 1 & & \\
\hline PR & PR2 & 0.62 & 0.55 & 0 & 1 & 0.54 & 0.62 \\
\hline Operation & $\mathrm{O} 1$ & 0.61 & & 0 & 1 & & \\
\hline $\mathrm{O}$ & $\mathrm{O} 2$ & 0.61 & 0.57 & 0 & 1 & 0.53 & 0.69 \\
\hline & D1 & 0.66 & & 0 & 1 & & \\
\hline Delivery & D2 & 0.6 & 0.62 & 0 & 1 & 0.66 & 0.68 \\
\hline & D3 & 0.46 & & 0 & 1 & & \\
\hline & MO1 & 0.48 & & 0 & 1 & & \\
\hline & MO2 & 0.67 & & 0 & 1 & & \\
\hline Modification & MO3 & 0.50 & 0.7 & 0 & 1 & 0.64 & 0.71 \\
\hline & $\mathrm{MO} 4$ & 0.70 & & 0 & 1 & & \\
\hline & MO5 & 0.74 & & 0 & 1 & & \\
\hline
\end{tabular}

TABLE IV. NUMBER OF CLUSTERS IN THREE ALGORITHMS BY USING SIX CLUSTER VALIDITY INDICES

\begin{tabular}{|c|c|c|c|c|c|c|c|}
\hline \multirow{2}{*}{ Algorithm } & \multicolumn{6}{|c|}{ Evaluation indices } & \multirow{2}{*}{ Frequency } \\
\hline & Wemmert-Gancarski & Ratkowsky-Lance & GDI11 & Dunn & Calinski-Harabasz & Davies-Bouldin & \\
\hline $\mathrm{HCA}$ & 6 & 4 & $6,7,8$ & $6,7,8$ & 4 & 5 & $6(3)$ \\
\hline SVM & 3 & 3 & 3 & 3 & 3 & 5 & $3(5)$ \\
\hline ICA & 3 & 3 & 5 & 5 & 3 & 8 & $3(3)$ \\
\hline
\end{tabular}

\section{DISCUSSION AND CONCLUSION}

Content analysis was used to identify dimensions of manufacturing flexibility. Then, experts were asked to provide their judgments on these dimensions and their relevance to industries existing in Iran. Content analysis showed that frequency, new product, production volume and machinery, respectively, were the most iterated dimensions in previous research. Considering different judgements of experts on relevance of these dimensions to the industries existing in Iran, content analysis of dimensions of manufacturing flexibility showed that priority of these dimensions is completely different for industrial organizations which seek for manufacturing 
flexibility in different dynamic environments and in different industries. This has also been noted in previous works $[5,6,12$, 17].

HCA, ICAs and SVMs were used for taxonomy, clustering and identifying dominant groups of manufacturing flexibility. The results of clustering were evaluated by using cluster validity indices. The results indicated three dominant groups of flexibility considering 14 dimensions of manufacturing flexibility; these groups were designated as delivery-based leading flexibility, frugal flexibility and plan-based sufficient flexibility. New product was the first to third priority in all groups, which indicates high importance of new product. Considering the change in customer needs and high competition in the market, it is particularly important to consider this dimension in all companies. This was not unexpected, because many previous studies such as $[6,11,17$, $21,23,25,28,29,31-36]$ have noted this previously. New product was the most iterated dimension (14 iterations) in content analysis. Unlike new product, production was the last dimension in three clusters; this indicates that production could not influence flexibility of Iranian industries or at least companies could not be flexible in this dimension. This can be attributed to mass production system used in majority of Iranian companies. This system is not flexible to changing needs of customers in minimum cost and short time. Routing was one of the last dimensions in all the clusters; this indicates weakness of manufacturing companies in implementing this dimension of flexibility in their production system. This can be attributed to lack of flexibility of mass production system and expensiveness of production through different routes for manufacturing companies. That is why companies are less likely to work on this dimension. Priority of dimensions of flexibility is different in most companies which are located in different clusters. Delivery is the first priority in the cluster 1, while it is the fourth priority in the cluster 2 and 3. Moreover, machinery is the first priority in the cluster 2 , while it is the eighth priority in the cluster

TABLE V. RESULTS OF EVALUATION INDICES FOR THE APPROPRIATE NUMBER OF CLUSTERS IN DIFFERENT ALGORITHMS

\begin{tabular}{|c|c|c|c|c|c|c|}
\hline \multirow[b]{2}{*}{ Algorithm } & \multicolumn{6}{|c|}{ Evaluation indices } \\
\hline & $\begin{array}{l}\text { Wemmert- } \\
\text { Gancarski }\end{array}$ & $\begin{array}{c}\text { Ratkowsky- } \\
\text { Lance }\end{array}$ & GDI11 & Dunn & $\begin{array}{l}\text { Calinski- } \\
\text { Harabasz }\end{array}$ & $\begin{array}{l}\text { Davies- } \\
\text { Bouldin }\end{array}$ \\
\hline HCA & 0.1771 & 0.2460 & 0.1442 & 0.1442 & 40.4149 & 1.6898 \\
\hline SVM & 0.2121 & 0.2716 & 0.1764 & 0.1764 & 55.8881 & 1.3823 \\
\hline ICA & 0.1572 & 0.2536 & 0.1442 & 0.1442 & 46.7893 & 1.0834 \\
\hline Optimum & 0.2121 & 0.2716 & 0.1764 & 0.1764 & 55.8881 & 1.0834 \\
\hline The best algorithm & SVM & SVM & SVM & SVM & SVM & $\mathrm{ICA}$ \\
\hline Appropriate number of clusters & 3 & 3 & 3 & 3 & 3 & 8 \\
\hline
\end{tabular}

TABLE VI. RESULTS OF CLUSTER ANALYSIS FOR CLASSIFYING MANUFACTURING COMPANIES BASED ON DIMENSIONS OF MANUFACTURING FLEXIBILITY

\begin{tabular}{|c|c|c|c|c|c|c|c|c|c|c|c|c|c|c|c|c|}
\hline Cluster & & Mi & $\mathbf{V}$ & $\mathbf{N}$ & Ma & MH & $\mathbf{E}$ & $\mathbf{L}$ & Ro & $\mathbf{P}$ & Mar & Pr & $\mathbf{O}$ & D & Mo & Industry \\
\hline \multirow{3}{*}{1} & Mean & 3.09 & 3.52 & 3.03 & 3.08 & 3.04 & 3.49 & 3.39 & 3.89 & 2.98 & 3.37 & 2.87 & 2.96 & 3.61 & 3.19 & \multirow{3}{*}{122} \\
\hline & WC rank & 7 & 2 & 10 & 8 & 9 & 3 & 4 & 13 & 11 & 5 & 14 & 12 & 1 & 6 & \\
\hline & $\mathrm{BC}$ rank & 1 & 1 & 1 & 3 & 2 & 1 & 1 & 2 & 2 & 1 & 1 & 2 & 1 & 1 & \\
\hline \multirow{3}{*}{2} & Mean & 2.72 & 3.06 & 2.78 & 3.34 & 2.83 & 2.98 & 2.97 & 2.91 & 2.47 & 2.93 & 2.7 & 2.75 & 2.97 & 2.87 & \multirow{3}{*}{116} \\
\hline & WC rank & 11 & 2 & 9 & 1 & 8 & 3 & 4 & 6 & 13 & 5 & 12 & 10 & 4 & 7 & \\
\hline & BC rank & 3 & 3 & 3 & 1 & 3 & 3 & 3 & 1 & 3 & 3 & 3 & 3 & 3 & 3 & \\
\hline \multirow{3}{*}{3} & Mean & 2.97 & 3.25 & 2.85 & 3.28 & 3.17 & 3.19 & 3 & 2.78 & 3.3 & 3.21 & 2.81 & 2.98 & 3.23 & 3.06 & \multirow{3}{*}{141} \\
\hline & WC rank & 11 & 3 & 12 & 2 & 7 & 6 & 9 & 14 & 1 & 5 & 13 & 10 & 4 & 8 & \\
\hline & $\mathrm{BC}$ rank & 2 & 2 & 2 & 2 & 1 & 2 & 2 & 3 & 1 & 2 & 2 & 1 & 2 & 2 & \\
\hline
\end{tabular}

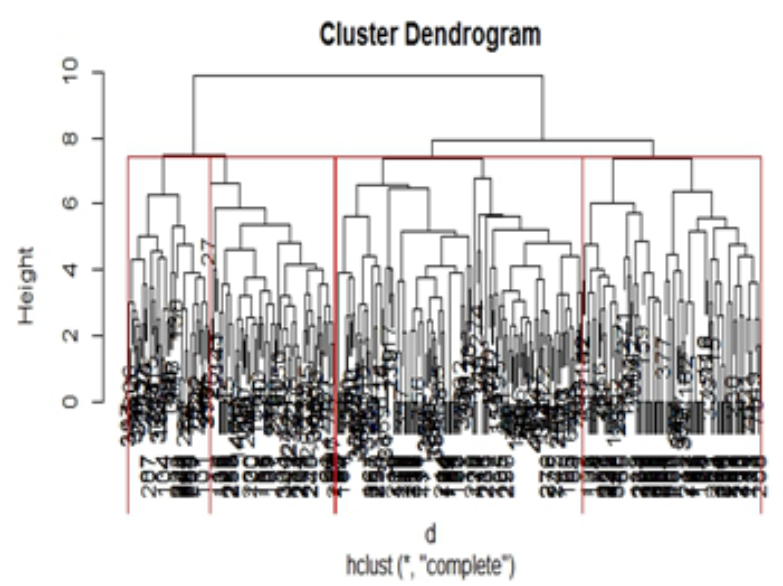

Fig. 1. Complete dendrogram for the 379 companies
- Plan is the first priority in the cluster 3 , while it is the eleventh priority in the cluster 1.

- These different priorities suggest that different industries do not use different dimensions of manufacturing flexibility similarly.

This has been supported by $[5,6,17]$. As the results show, food and beverage industry is the most frequent industry in cluster 1; metal, chemical and textile industries are the most frequent industries in cluster 2; electrical and electronics, cellulose and non-metallic minerals are the most frequent industries in cluster 3 . This indicates the difference of these industries in using dimensions of manufacturing flexibility. Managers of industrial organizations can identify dimensions of flexibility which are effective on their industrial organization by considering their relevant industry and determining their flexibility cluster. Moreover, managers of manufacturing 
companies should selectively implement dimensions of manufacturing flexibility identified in the present study, because academic and industrial experts identified considerable differences in prioritization of these dimensions.

\section{REFERENCES}

[1] A. Cingoz, A. A. Akdogan, "Strategic Flexibility, Environmental Dynamism, and Innovation Performance: An Empirical Study", Procedia - Social and Behavioral Sciences, Vol. 99, No. 1, pp. 582-589, 2013

[2] S. Genchev, G. Willis, "A note on manufacturing flexibility as a firmspecific dynamic capability", Manufacturing Letters, Vol. 2, No. 3, pp. 100-103, 2014

[3] G. Copani, M. Urgo, "New business models and configuration approachesfor focused-flexibility manufacturing systems", Procedia CIRP, Vol. 2, No. 5, pp. 10-15, 2012

[4] D. Upton, "The Management of Manufacturing Flexibility", California Management Review, Vol. 1, No. 1, pp. 72-88, 1994

[5] G. Seebacher, H. Winkler, "Evaluating Flexibility in Discrete Manufacturing Based on Performance and Efficiency", International Journal of Production Economics, Vol. 153, No. 2, pp. 340-351, 2014

[6] R. J. Vokurka, S. W. O Leary-Kelly, "A review of empirical research on manufacturing flexibility", Journal of Operations Management, Vol. 18, No. 2, pp. 485-501, 2000

[7] S. Kara, B. Kayis, "Manufacturing flexibility and variability: an overview", Journal of Manufacturing Technology Management, Vol. 15, No. 6, pp. 466-478, 2004

[8] A. Oke, "A framework for analysing manufacturing flexibility", International Journal of Operations and Production Management, Vol. 25, No. 10, pp. 973-996, 2005

[9] J. H. Saleh, G. Mark, N. C. Jordan, "Flexibility: a Multi-Disciplinary Literature Review and a Research Agenda for Designing Flexible Engineering Systems", Journal of Engineering Design, Vol. 20, No. 3, pp. 307-323, 2009

[10] T. A. Boyle, M. S. Rathje, "An empirical examination of the best practices to ensure manufacturing flexibility Lean alignment", Journal of Manufacturing Technology Management, Vol. 20, No. 3, pp. 348-366, 2009

[11] Y. P. Gupta, T. M. Somers, "Business strategy, manufacturing flexibility, and organizational performance relationships: a path analysis approach", Production and Operations Management, Vol. 5, No. 3, pp. 204-233, 1996

[12] S. Gustavsson, "Flexibility and productivity in complex processes", International Journal of Production Research, Vol. 22, No. 5, pp. 801808,1988

[13] K. Boyer, G. K. Leong, P. T. Ward, L. J. Krajewski, "Unlocking the potential of advanced manufacturing technologies", Journal of Operations Management,Vol. 15, No. 4, pp. 331-347, 1997.

[14] P. Nemetz, Bridging the strategic outcome measurement gap in manufacturing organizations, in Ettlie, J.E., Burstein, M.C, 1990.

[15] F. F. Suarez, M. A. Cusumano, C. H. Fine, "An empirical study of manufacturing flexibility in printed circuit board assembly", Operations Research, Vol. 44, No. 1, pp. 223-49, 1996.

[16] C. H. Wood, L. P. Ritzman, D. Sharma, Intended and achieved competitive priorities: measures, frequencies and financial impact, in Ettlie, J.E., Burstein, M.cC. and Feigenbaum, A. (Eds), Manufacturing Strategy, Kluwer Academic Publishers, Boston, MA, 1990.

[17] S. H. Chang, R. J. Lin, J. Chen, L. H. Huang, "Manufacturing Flexibility and Manufacturing Proactiveness Empirical Evidence from the Motherboard Industry", Industrial Management \& Data Systems, Vol. 105, No. 8, pp. 1115-1132, 2005.

[18] J. Browne, D. Dubois, K. Rathmil, S. P. Sethi, K. E. Stecke, (1984)Classification of Flexible Manufacturing Systems", The FMS Magazine, Vol. 2, No. 2, pp. 114-117, 1984.

[19] S. H. Chang, C. L. Yang, H. C. Cheng, C. Sheu, "Manufacturing Flexibility and Business Strategy: An Empirical Study of Small and
Medium Sized Firms", International Journal of Production Economics, Vol. 83, No. 3, pp. 13-26, 2003

[20] C. Gaimon, V. Singhal, "Flexibility and The Choice of Manufacturing Facilities Under Short Product Life Cycles", European Journal of Operational Research, Vol. 60, No. 2, pp. 211-223, 1992

[21] L. L. Koste, M. K. Malhotra, "A theoretical framework for analyzing the dimensions of manufacturing flexibility", Journal of Operations Management, Vol. 18, No. 2, pp. 75-93, 1999

[22] P. S. Adler, "Managing Flexible Automation", California Management Review, Vol. 30, No. 3, pp. 34-56, 1988

[23] R. Mishra, A. P. Pundir, G. Ganapathy, "Assessment of manufacturing flexibility", A review of research and conceptual Framework, Management Research Review, Vol. 37, No. 8, pp. 750-776, 2014

[24] D. M. Upton, "The management of manufacturing flexibility", California Management Review, Vol. 2, No. 36, pp. 72-89, 1997

[25] A. D. Toni, S. Tonchia, "Definition and linkages Between Operational and Strategic Flexibilities", Omega, Vol. 33, No. 4, pp. 525-540, 2005

[26] A. Oke, "Linking manufacturing flexibility to innovation performance in manufacturing plants", Journal Production Economics, Vol. 143, No. 4, pp. $242-247,2013$

[27] Y. P. Gupta, S. Goyal, "Flexibility of Manufacturing Systems: Concepts and Measurement", European Journal of Operational Research, Vol. 43, No. 4, pp. 119-135, 1989

[28] R. Beach, A. P. Muhleman, D. H. R. Price, A. Paterson, J. A. Sharp, "Review of Manufacturing Flexibility", European Journal of Operational Research, Vol. 122, No. 2, pp. 41-57, 2000

[29] R. Narain, R. C. Yadav, J. Sarkis, J. J. Cordeiro, "The strategic Implications of Flexibility in Manufacturing Systems", International Journal of Agile Management Systems,Vol. 2, No. 3, pp. 202-213, 2000

[30] R. V. Ramesesh, M. D. Jayakumar, "Measurement of manufacturing flexibility: a value based approach", Journal of Operations Management, Vol. 10, No. 4, pp. 446-69, 1991

[31] A. K. Sethi, S. P. Sethi, "Flexibility in manufacturing: a survey", International Journal of Flexible Manufacturing Systems, Vol. 2, No. 4, pp. $289-328,1990$

[32] A. Y. Chang, "Prioritising the types of manufacturing flexibility in an uncertain environment", International Journal of Production Research, Vol. 50, No. 8, 2133-2149, 2012

[33] R. Sawhney, "Interplay between uncertainty and flexibility across the value-chain:Towards a transformation model of manufacturing flexibility", Journal of Operations Management,Vol. 24, No. 2, pp. 476493, 2006

[34] C. P. Patel, "Role of manufacturing flexibility in managing duality of formalization and environmental uncertainty in emerging firms", Journal of Operations Management, Vol. 29, No. 3, pp. 143-162, 2011

[35] L. K. Koste, M. K. Malhotra, S. Sharma, "Measuring dimensions of manufacturing flexibility", Journal of Operations Management, Vol. 22, No. 3, pp. 171-196, 2004

[36] N. Slack, "Flexibility as A Manufacturing Objective", International of Operations and Production Management,Vol. 3, No. 3, pp. 5-13, 1983

[37] B. Dreyer, K. Gronhaug, "Uncertainty, flexibility, and sustained competitive advantage", Journal of Business Research ,Vol. 57, No. 2, pp. 484-494, 2004

[38] G. N. Punj, D. W. Stewart, "Cluster Analysis in marketing redearch: Review and suggestions for application", Journal of Marketing Research, Vol. 20, No. 2, pp. 134-148, 1983

[39] M. Sattlecker, R. Baker, N. Stone, C. Bessant, "Support vector machine ensembles for breast cancer type prediction from mid-FTIR microcalcification spectra", Chemometrics and Intelligent Laboratory Systems, Vol. 107, No. 2, pp. 363-70, 2011

[40] E. Atashpaz-Gargari, C. Lucas, "Imperialist Competitive Algorithm: An Algorithm for Optimization inspired by imperialistic Competition", IEEE Congress on Evolutionary Computation, Singapore, Vol. 4, No. 3, pp. $4661-67,2007$

[41] A. Kaveh, S. Talatahari, "Optimum design of skeletal structures using imperialist competitive algorithm", Computers \& Structures, Vol. 88, No. 3, pp. 1220-1229, 2010 
[42] T. Niknam, E. Taherian Fard, N. Pourjafarian, A. Rousta, "An efficient hybrid algorithm based on modified imperialist competitive algorithm and K-means for data clustering", Engineering Applications of Artificial Intelligence, Vol. 24, No. 2, pp. 306-317, 2011

[43] C. Lucas, Z. Nasiri-Gheidari, F. Tootoonchian, "Application of an imperialist competitive algorithm to the design of a linear induction motor", Energy Conversion and Management, Vol. 51, No. 7, pp. 14071411,2010

[44] A. Khabbazi, E. Atashpaz-Gargari, C. Lucas, "Imperialist competitive algorithm for minimum bit error rate beamforming", International Journal of Bio-Inspired Computation,Vol. 1, No. 1, pp. 125-133, 2009
[45] J. C. Bezdek, N. R. Pal, "Some new indexes of cluster validity", IEEE Transactions on Systems, Man, and Cybernetics NPART B: CYBERNETICS, Vol. 28, No. 3, pp. 301-315, 1988

[46] B. Desgraupes, “clusterCrit: Clustering Indices", R package version,Vol. 1, No. 3, pp. 4-5, 2013. http://CRAN.R-project.org/package=clusterCrit.

[47] K. P. Agrawal, S. Garg, P. Patel, "Performance Measures for Densed and Arbitrary Shaped Clusters", International Journal of Computer Science \& Communication, Vol. 6, No. 2, pp. 338-350, 2015 